\title{
The impacts of physical processes on oxygen variations in the North Sea-Baltic Sea transition zone
}

\author{
L. Jonasson ${ }^{1,2}$, J. L. S. Hansen ${ }^{3}$, Z. Wan ${ }^{1}$, and J. She ${ }^{1}$ \\ ${ }^{1}$ Danish Meteorological Institute, Lyngbyvej 100, 2100 Copenhagen, Denmark \\ ${ }^{2}$ Niels Bohr Institute, University of Copenhagen, Juliane Maries Vej 30, 2100 Copenhagen, Denmark \\ ${ }^{3}$ National Environmental Research Institute, Aarhus University, Frederiksborgvej 399, 4000 Roskilde, Denmark \\ Correspondence to: L. Jonasson (laj@dmi.dk)
}

Received: 25 February 2011 - Published in Ocean Sci. Discuss.: 15 July 2011

Revised: 25 November 2011 - Accepted: 12 December 2011 - Published: 24 January 2012

\begin{abstract}
The bottom water of the North Sea-Baltic Sea transition zone suffers from seasonal hypoxia, usually during late summer and autumn. These hypoxic events are critical for the benthic ecosystems and the concentration of dissolved oxygen is an important measure of the water quality. However, to model the subsurface dissolved oxygen is a major challenge, especially in estuaries and coastal regions. In this study a simple oxygen consumption model is coupled to a 3-D hydrodynamical model in order to analyse oxygen variations in the transition zone. The benthic and pelagic consumption of oxygen is modelled as a function of water temperature and oxygen concentration. A quantitative assessment of the model demonstrates that the model is able to resolve both seasonal and interannual variations in dissolved oxygen. Results from several experimental simulations highlight the importance of physical processes in the regulation of dissolved oxygen. Advective oxygen transport and wind induced mixing are two key processes that control the extent of hypoxia in the transition zone.
\end{abstract}

\section{Introduction}

The transition zone between the North Sea and the Baltic Sea is in this study defined to range from the Northern Kattegat to Arkona Basin. This area limits the water exchange between these two seas because of a complex topography with several narrow straits and shallow sills. The circulation is characterized by inflowing high saline bottom water from the North Sea and outflowing low saline water from the Baltic Sea.
This two layer flow is often interrupted by large barotropic transports which are driven by sea level difference between the North Sea and the Arkona Basin. The water column is stratified with a sharp halocline which is only occasionally destroyed by strong mixing events. The stratification is usually enhanced during summer by the development of a thermocline. The strong stratification in combination with a high productivity leads to an imbalance between the consumption and supply of dissolved oxygen (DO) to the bottom water and seasonal hypoxia is a recurring problem. Severe hypoxia, defined as $<63 \mathrm{moll}^{-1}$ (HELCOM, 2003; Diaz, 2001), occurs locally in late summer and autumn and persists until either local DO supply from the surface or advective water exchange re-oxygenates the bottom water.

DO concentration was observed to decline in the 1980's (Andersson and Rydberg, 1988) which has been attributed to the large increase in nutrient input. The nutrient loads from land are believed to have been more than doubled from 1950 to 1980 because of the wide spread usage of fertilizers, increase in population and a growing agriculture industry (Conley et al., 2007). During the last two decades several measures have been taken to decrease the discharge of nitrogen and phosphorus to this region and Carstensen et al. (2006) reported a trend of reduced nutrient concentrations in the water. However, decreasing eutrophication has not yet been accompanied with improved oxygen conditions. The oxygen consumption in the bottom water is related to the nutrient loads through the remineralisation of organic matter that sinks from the productive layer to the bottom water. A reduction in nutrient input could in principle reduce the primary production and thereby the export 
of organic material. Aerobe remineralisation of organic material is the most important oxygen sink (Xu and Hood, 2006; Oguz et al., 2000) but the DO concentration is also influenced by chemical oxidation of reduced substances from anaerobic remineralisation of organic matter in the sediment and the linkage between nutrient loads and DO is highly nonlinear. In other words, the coupling between primary production, export production and oxygen consumption is far from being resolved (Olesen and Lundsgaard, 1995; Gray et al., 2002).

DO is supplied to the bottom water in the transition zone mainly through horizontal advection of Skagerrak water and vertical mixing of the water column. Both wind and inflows are subjected to a clear annual cycle with lower wind speeds and less inflows in summer than in winter. These physical processes regulate the extent and timing of hypoxia and have a large influence on the interannual oxygen conditions. By using an age traces technique, Bendtsen et al. (2009) examine the distribution of the processes and concluded that advected Skagerrak water dominates the ventilation in Kattegat whereas vertical mixing is important in Great Belt and Western Baltic Sea.

In this study we focus on the importance of physical processes in modulating the seasonal and interannual variation of DO in the transition zone. A hydrodynamical 3D model coupled with the simplified oxygen consumption model OXYCON (Hansen and Bendtsen, 2009) is established to simulate the DO variations. In this way the physical processes are modelled with a state-of-the-art technique while the more uncertain biogeochemical processes are simplified as much as possible. The aims of this paper are to assess the capability of the coupled models to simulate the hypoxic events and to evaluate the importance of physical processes in regulating the interannual and seasonal DO variations.

\section{Method}

\subsection{Physical model}

The physical model code used in this study was DMIBSHcmod (She et al., 2007) which previously ran operationally at the Danish Meteorological Institute (DMI) to produce forecast for the Danish and nearby waters. The model is based on Navier-Stokes primitive equations which are spatially discretized with a finite difference method. The discrete equations are closed with a Smagorinsky formulation for the horizontal diffusivity and a two-equation k- $\omega$ scheme for the vertical turbulence. In this study, the model runs on a two-way nested domain with a coarse domain $(6 \mathrm{~nm}, 50$ vertical layers) covering the North Sea and Baltic Sea and a fine resolution domain $(1 \mathrm{~nm}, 52$ vertical layers) in the transition zone (Fig. 1). The vertical resolution in the coarse grid varies between $2-50 \mathrm{~m}$ and in the fine grid between $1-2 \mathrm{~m}$. Some special consideration is needed when constructing the

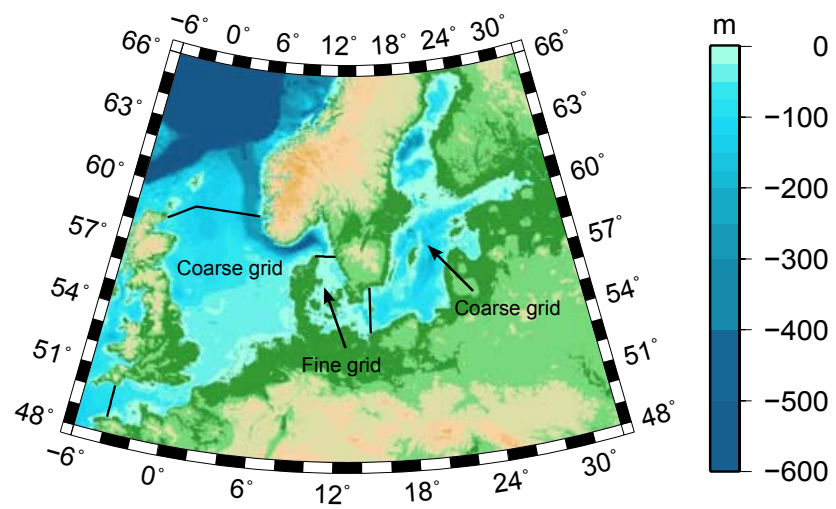

Fig. 1. The two-way nested domain for the physical model.

vertical grid structure because the model is not able to handle a completely dry grid point. In order to comply with this constraint the surface layer has to be thicker than the minimum sea level. A surface layer thickness of $8 \mathrm{~m}$ is used in the coarse domain but in the fine domain the sea level amplitude is smaller and a surface layer of $2 \mathrm{~m}$ is enough. The vertical grid structure can be seen in Table 1. Climatologies of salinity and temperature are applied along the outer lateral boundaries as well as tidal constituents and sea level elevation from a 2-D version of DMI-BSHcmod covering the north Atlantic. 79 rivers are included in the setup of which 9 is enclosed by the fine domain. Daily freshwater input is collected from observational data for 5 German rivers, model data for 43 catchment areas from the HBV model run at Swedish Meteorological and Hydrological Institute (SMHI) and as a last resort climatological data is used. The model was forced with hourly meteorological data based on the operational weather model DMI-HIRLAM. The meteorological forcing includes wind, air temperature, sea level pressure, surface humidity and cloud cover. Salinity and temperature data from operational model runs at the Danish Meteorological Institute (DMI) was used as initial fields and the model ran $1.5 \mathrm{yr}$ (July 2000-December 2001) before any experimental simulations was carried out.

\subsection{Oxygen model}

The oxygen consumption model (OXYCON) is developed by Hansen and Bendtsen (2009). This water column model was coupled to DMI-BSHcmod through an operator splitting scheme where first advection and diffusion of DO are calculated and thereafter the biochemical sinks and sources. In short, the model considers one pelagic oxygen sink and two benthic sinks due to microbial and macrofaunal respiration, and furthermore, it is assumed that the pools of organic carbon available for remineralisation in the sediment and suspended in the water column are almost constant. The temporal variation in remineralisation is determined by the temperature sensitivity of the process and the 
Table 1. Vertical grid structure.

\begin{tabular}{lc|lc}
\hline \multicolumn{2}{c}{ Coarse grid } & \multicolumn{2}{c}{ Fine grid } \\
\hline Layer & Thickness [m] & Layer & Thickness [m] \\
\hline 1 & 8 & 1 & 2 \\
$2-37$ & 2 & $2-29$ & 1 \\
38 & 4 & $30-52$ & 2 \\
$39-40$ & 8 & & \\
$41-42$ & 25 & & \\
$43-50$ & 50 & & \\
\hline
\end{tabular}

benthic remineralisation rates also depend on the near bottom DO concentration. The model parameters are calibrated by Hansen and Bendtsen (2009) to tune the annual average oxygen consumption below the halocline to approximately $80 \mathrm{~g} \mathrm{C} \mathrm{m}^{-2}$. The concentration of particulate organic carbon (POC) in the bottom water is assumed to be balanced by the input of POC from the productive layer and the removal of POC due to remineralisation and deposition. As the remineralisation rate is $2-3$ times higher in summer than winter in the bottom water the flux of organic carbon is assumed to increase correspondingly. The increase in POC flux from spring to late summer is consistent with the study of POC in the area by Olesen and Lundsgaard (1995), they also found an almost constant concentration of POC in the bottom water during March-October. The division of the oxygen consumption into benthic and pelagic remineralisation is very important in order to resolve the spatial and temporal distribution of oxygen consumption in the area. OXYCON model equations and parameters are presented in Appendix A. A detailed description of the model is presented in Hansen and Bendtsen (2011) where they show that OXYCON is able to simulate DO when coupled to two different physical models.

Though this model greatly simplifies the oxygen dynamics, the underlying assumptions are consistent with observations. However, the fact that the model does not resolve the dynamical link between the bottom water respiration and the new production in the euphotic zone imposes some strong model limitations. First, the annual export production is based on empirical data and the model can not capture interannual variations in the annual oxygen consumption and long-term eutrophication trends are not resolved. Secondly, short-term peaks in the flux of organic material across the halocline are also unresolved. However, these peaks in the flux of organic matter are often campaigned with increased sedimentation rates because of aggregate formation (Kiørboe et al., 1994). Therefore mass sedimentation events are exposed to pelagic respiration in the bottom water for a relatively short time and the specific oxygen consumption of this material in the water column is reduced. Instead, the material will to a larger extent be incorporated into the sediment pool of organic material where the short-term variability in the remineralisation rate is not expected. The simplifications made will course reduce the range of applications for this model but the resolution is sufficient for the designed experiments in this study. Furthermore, the fact that this simple treatment of the carbon dynamics is able to resolve the oxygen variations in this region highlights the importance of physical processes. The choice of model differs significantly from the more complex biogeochemical models available for this region. ERGOM coupled to DMI-BSHcmod has been proven useful in process studies in the euphotic zone (Wan et al., 2011) and Maar et al. (2011) validated the model for the surface water. However, this model setup is yet to be validated for the bottom DO in the Transition zone.

The DO concentration of the inflowing North Sea water is an important factor for the oxygen conditions in the Kattegat but the strongly parameterized OXYCON can not accurately simulate the DO outside the Transition zone. For this reason, oxygen data from a monitoring station in Skagerrak was extracted from the Swedish Meteorological and Hydrological Institute's (SMHI) database SHARK and applied as boundary condition at the northern border of the fine and coarse grid. The boundary to the Baltic Sea needed no special consideration because the Baltic Sea outflow mainly occurs at the surface where both model and observations were close to $100 \%$-saturation. The oxygen model was initialised with $100 \%$ saturation in July 2000.

\subsection{Model assessment}

To produce a confident and qualitative assessment of a model it is important to first identify the purpose of the model (Rykiel, 1996). This is a crucial step of the assessment process which must not be foreseen. The purpose of the model in study was to simulate the seasonal and interannual oxygen variations and the hypoxic events in the transition zone. As the hypoxic events occur below the pycnocline and usually in the autumn months the model should ideally be assessed during this season and below the main pycnocline which is situated at $15 \mathrm{~m}$. Another important consideration is what kind of statistical measures to use. Here we have used a combination of several metrics: bias, root mean square difference (RMSD), absolute average error (AAE), centered root mean square difference (cRMSD) and model efficiency (MEF). The mathematic formulation for each metric is given below in Eqs. (1-5). The bias, the RMSD and the AAE is commonly used in model validation but the cRMSD and MEF might need some further explanation. The cRMSD is the unbiased root mean square difference (RMSD) and can be seen as the combined effect of misfits in amplitude and the correlation. The model efficiency (MEF) in Eq. (5) was introduced by Nash and Sutcliffe (1970) and produces a model skill score which can easily be compared to other models. It compares the model-observation mismatch with the variability of the observations and the performance is 
usually categorized as seen in Table 2 (Vichi and Masina, 2009; Lewis and Allen, 2009).

$\mathrm{RMSD}=\sqrt{\frac{1}{n} \sum_{i=1}^{n}\left(\operatorname{Model}_{i}-\mathrm{Obs}_{i}\right)^{2}}$

bias $=\frac{1}{n} \sum_{i=1}^{n} \operatorname{Model}_{i}-\frac{1}{n} \sum_{i=1}^{n} \operatorname{Obs}_{i}$

$\mathrm{AAE}=\frac{1}{n} \sum_{i=1}^{n}\left|\operatorname{Model}_{i}-\mathrm{Obs}_{i}\right|$

$\mathrm{cRMSD}=\sqrt{\mathrm{RMSD}^{2}-\text { bias }^{2}}$

$\mathrm{MEF}=1-\frac{\mathrm{RMSD}^{2}}{\sigma_{\mathrm{o}}^{2}}$

The physical model has been assessed in earlier studies (She et al., 2007; Larsen et al., 2007) and in this context the performance of the model will only be documented by comparison of modelled and observed salinity and temperature for station "gb" in Fig. 2. The oxygen model was thoroughly assessed by the usual time series analysis, where model and observations were compared at the four stations seen in Fig. 2. The observations were gathered from SHARK and the National Environmental Research Institute's (NERI) database MADS. With time series analysis it is easy to visualise and follow the model-observation miss-match in time but a major disadvantage is that we do not get any information of the spatial error distribution. To account for this, all available observations in the autumn months (August-October) during the period 2002-2006 were collected from the International Council for the Exploration of the Sea's (ICES) database and model-observations pairs below $15 \mathrm{~m}$ depth were gathered into a grid in which the statistical measures were calculated.

\subsection{Sensitivity experiments}

Four different experimental simulations were performed and compared to a reference simulation during the period 20022004. In each simulation the transport below $15 \mathrm{~m}$ across two sections was measured (Fig. 2). The inflow of Skagerrak water was measured in the Northern Kattegat section (S1) and the flow through Great Belt at the centre of the strait (S2) by summing up the integrated velocities at every time step and store the daily accumulated transports across each transect.

The first two experiments were similar and can be seen as a sensitivity analysis of the seasonality of DO. In the first experiment (Simulation 1), the seasonality of the three respiratory sinks were removed by setting each respiration rate to its respective annual mean. The second sensitivity experiment (Simulation 2) concerned the effect of seasonally variable oxygen solubility. In the latter scenario the concentration of

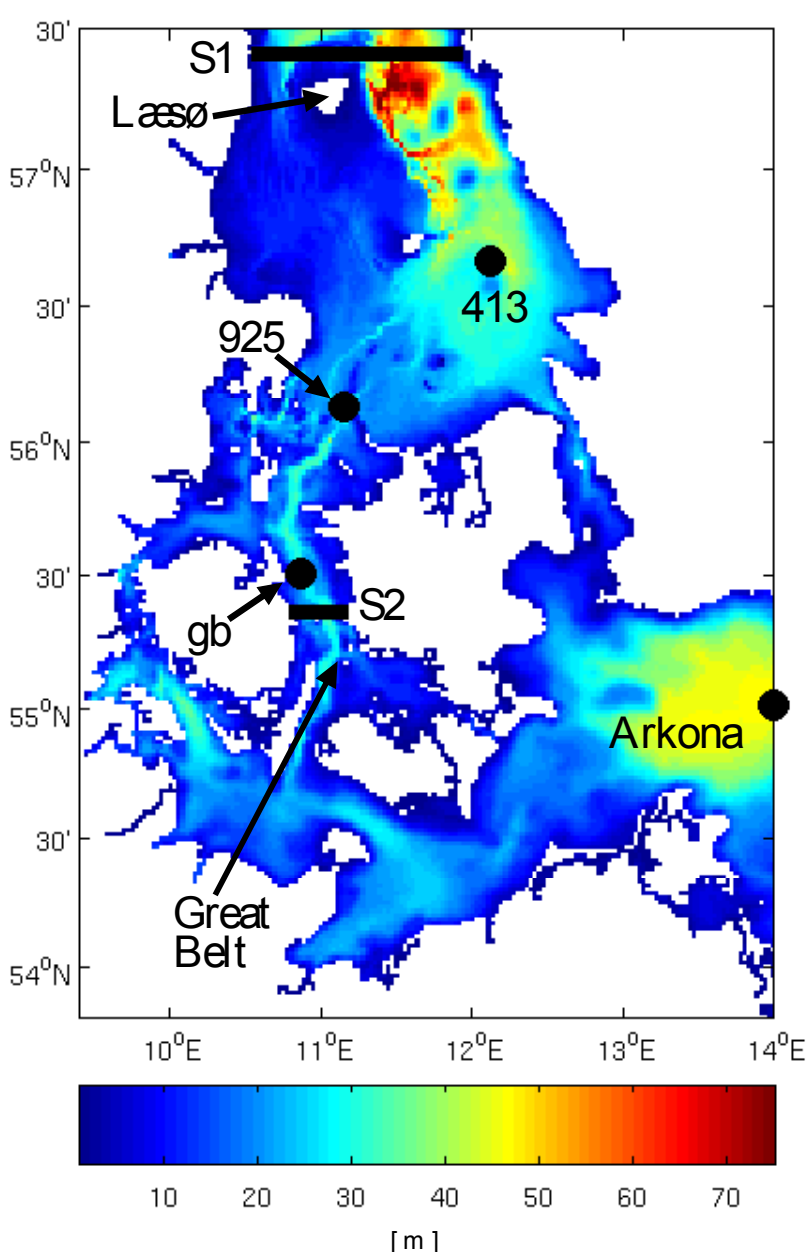

Fig. 2. The North Sea - Baltic Sea transition zone with model bathymetry. Monitoring stations used in the model assessment are indicated with black dots and the two cross sections with black lines.

Table 2. MEF performance levels.

\begin{tabular}{ll}
\hline$>0.65$ & Excellent \\
$0.5-0.65$ & Very good \\
$0.2-0.5$ & Good \\
$0-0.2$ & Poor \\
$<0$ & Worse than \\
& observation mean
\end{tabular}

DO in the surface water was kept constant, as opposed to the real situation where the oxygen solubility is determined by temperature, salinity and to a minor degree pressure.

It is well known that the wind speed during the autumn months has a pronounced effect on the DO conditions in the transition zone, especially in estuaries and coastal areas (Møhlenberg, 1999; HELCOM, 2003). High wind speeds will weaken the stratification and bring DO rich surface 
a)

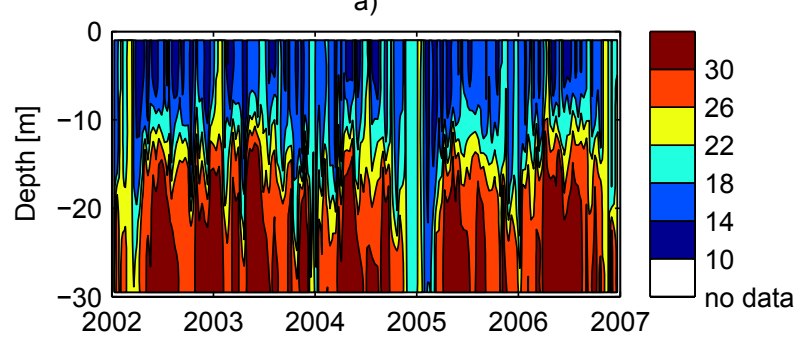

c)

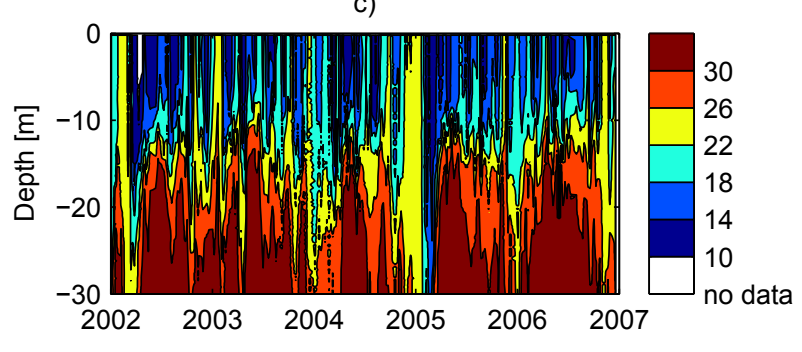

b)

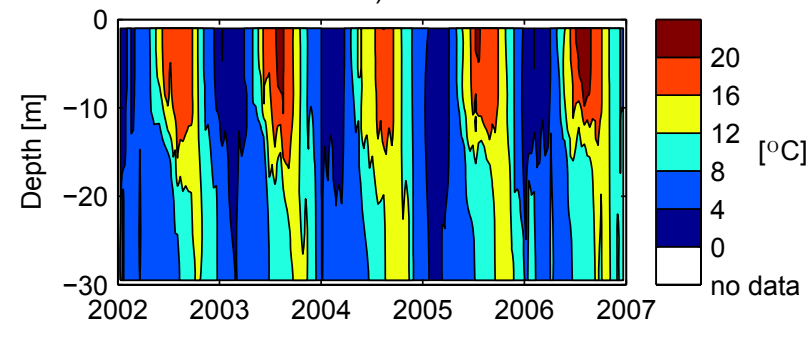

d)

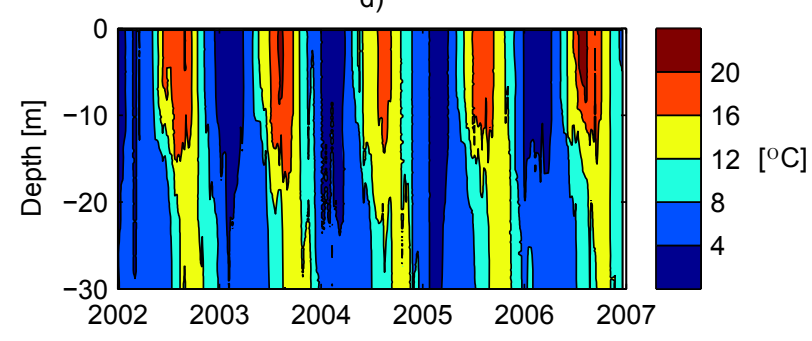

Fig. 3. Simulated and observed salinity and temperature for station "gb" in Great Belt: (a) modelled salinity, (b) modelled temperature, (c) observed salinity, (d) observed temperature.

water across the pycnocline. The wind also influences the circulation and Skyum et al. (1994) described how vertical movement of the pycnocline in Kattegat influenced the DO concentrations at the Danish coasts. Many previous studies focus on data from a specific fjord or estuary (Møhlenberg, 1999) but equipped with this 3-D model it is possible to quantitatively describe the impact of wind driven mixing, not only at monitoring stations, but in the whole model domain. The hypoxia in 2002 was one of the most severe events ever recorded and the hypoxic area was up to $9200 \mathrm{~km}^{2}$ (HELCOM, 2003) while two years after, in 2004, the oxygen condition was better than normal. A comparison of the wind in August and September for these two years revealed that the average wind in 2004 was $15 \%$ and $27 \%$ higher than in 2002 , respectively. In order to investigate the relationship between hypoxia and wind speed, two experimental simulations were designed. In the first wind experiment (Simulation 3), the model was started with initial field from the reference simulation in 1 July 2002 and run until 30 November 2002 and in September the $u$ and $v$ wind components were increased by $27 \%$ in order to reach the same monthly September mean as in 2004. The second wind experiment (Simulation 4) had a similar design but here the model was started with initial fields from the reference simulation in 1 July 2004 and run until 30 November 2004 with the September wind speed decreased by $21.3 \%$ in order to reach the same monthly mean as September 2002. A summary of all simulations can be seen in Table 3 .

\section{Results}

\subsection{Model assessment}

\subsubsection{Physical model}

One of the most important aspects for oxygen modelling is a well resolved stratification, both in strength and vertical position, because the stratification acts as a barrier for the bottom water ventilation. In Fig. 3 model output of salinity and temperature is shown together with observations for Great Belt. The depth of the halocline was $15 \mathrm{~m}$ in both model and observations and the salinity profile was well described. The model simulated mixing events very well, as can be seen during the storm Gudrun in the beginning of 2005. Modelled variations in temperature were also consistent with the observations with a development of a thermocline at $15 \mathrm{~m}$ depth in summer. Since the surface temperature is more or less determined from the atmospheric forcing the model performance should rather be assessed from the resolution of the bottom temperature. The model succeeded in simulating the downward convection of warm surface water and cold winter water which is a good indication of a sound turbulence scheme. Based on previous studies and visual inspection the conclusion is that the model is able to simulate the main features of this area.

\subsubsection{Oxygen model}

In Arkona Basin the absolute average error AAE exceeded $50 \mu \mathrm{moll}^{-1}$ but for the remaining stations the AAE ranged between $22-40 \mu \mathrm{moll}^{-1}$ (Fig. 4). The three stations in 
Table 3. Preformed simulations.

\begin{tabular}{lll}
\hline & Period & Description \\
\hline Validation & $2002-2006$ & The reference and assessment simulation \\
Simulation 1 & $2002-2004$ & Constant respiration \\
Simulation 2 & $2002-2004$ & Constant oxygen solubility \\
Simulation 3 & Jul 2002-Nov 2002 & Increased September wind \\
Simulation 4 & Jul 2004-Nov 2004 & Decreased September wind \\
\hline
\end{tabular}

Kattegat and Great Belt all showed a negative bias and the DO concentration seemed to be underestimated during winter and spring, however the minimum oxygen in autumn was well described. The negative bias was likely caused by insufficient mixing, too high respiration rate during winter or that the model does not considered mixing and advection of oxygen oversaturated water during the spring bloom. Both model and observations at Station 413 showed a nearly linear decrease of DO during spring and summer while the variability was larger further to the south, probably because of a weaker stratification, a stronger influence from vertical mixing or influence from coastal water masses. Not shown in Fig. 4 is the model efficiency, this value ranged between $0.4-0.5$ and the performance can be categorized as "good" (Table 2). It is not surprising that the error is largest in Arkona Basin because the model is parameterized for the Kattegat and the Belt Seas. Parameters and processes such as higher productivity, nitrogen fixation and coupling between bottom water respiration and primary production are not resolved in OXYCON. Furthermore, the performance of the physical model was better in the Danish straits than in Arkona Basin (comparison not shown).

More than 3000 observation were collected and used in the spatial validation and the overall metric estimates are presented in Table 4. It shows an overall negative bias and an average error of $38 \mu \mathrm{moll}^{-1}$. The model efficiency index was 0.48 which by using the categorization in Table 3 places the model in the upper limit of "good". The spatial error distribution revealed a distinct gradient from north to south with errors increasing southward (Fig. 5). This was most probably because of the decreased impact from the northern boundary condition. The bias distribution showed that the model underestimated the DO concentrations in southern Kattegat and Arkona Basin and overestimated it in Mecklenburg Bight. It should also be mentioned that the error in Arkona Basin might be underestimated because the halocline is deeper than $15 \mathrm{~m}$ and some surface water was included in the calculations. All in all, the performance of OXYCON was good and we conclude that the model is able to simulate the spatial distribution of DO and oxygen depletion events.
Table 4. Oxygen model assessment indices. 3149 modelobservation pairs were collected between August-October below $15 \mathrm{~m}$ depth for the years 2002-2006.

\begin{tabular}{lr}
\hline Measure & Result \\
\hline Bias & $-8.7 \mu \mathrm{moll}^{-1}$ \\
AAE & $38.4 \mu \mathrm{moll}^{-1}$ \\
RMSD & $52.6 \mu \mathrm{moll}^{-1}$ \\
MEF & 0.48 \\
\hline
\end{tabular}

\subsection{Seasonal variations}

The results from Simulation 1 and 2 can be seen in Fig. 6 together with the reference simulation. Averaged over the three years, the mean bottom water DO concentration varied between $330 \mu \mathrm{moll}^{-1}$ in March and a $150 \mu \mathrm{moll}^{-1}$ in September/October. Arkona basin was excluded in the calculation of the mean DO concentration because the halocline is much deeper than $15 \mathrm{~m}$. As expected, the seasonal variation in both experimental simulations was lower than in the reference simulation. However, compared to the reference case, the decrease in seasonality in the two simulations were relatively small. The amplitude of the seasonal variation was decreased by only $13 \%$ and $24 \%$ in Simulation 1 and 2, respectively. However, even though the change in mean bottom DO concentration was small, it should be mentioned that the average value covers a large geographic range in transition zone from the northernmost well oxygenated areas to the southern parts close to the Baltic Sea which are frequently subjected to hypoxia. The seasonal variation in respiration rate becomes increasingly significant the further south in the area where the water has been affected by oxygen consumption for a longer time. Hence, oxygen conditions may locally be very sensitive to such changes and the extent of hypoxia was less in both simulations, especially in shallow areas (spatial pattern not shown).

The monthly average wind speed over 2002-2004 (Fig. 7a) in the fine domain (Arkona Basin excluded) was 6.4 and $8.0 \mathrm{~m} \mathrm{~s}^{-1}$ during summer (May-August) and winter (November-February), respectively. The maximum wind speed also showed a clear annual cycle with stronger winds 

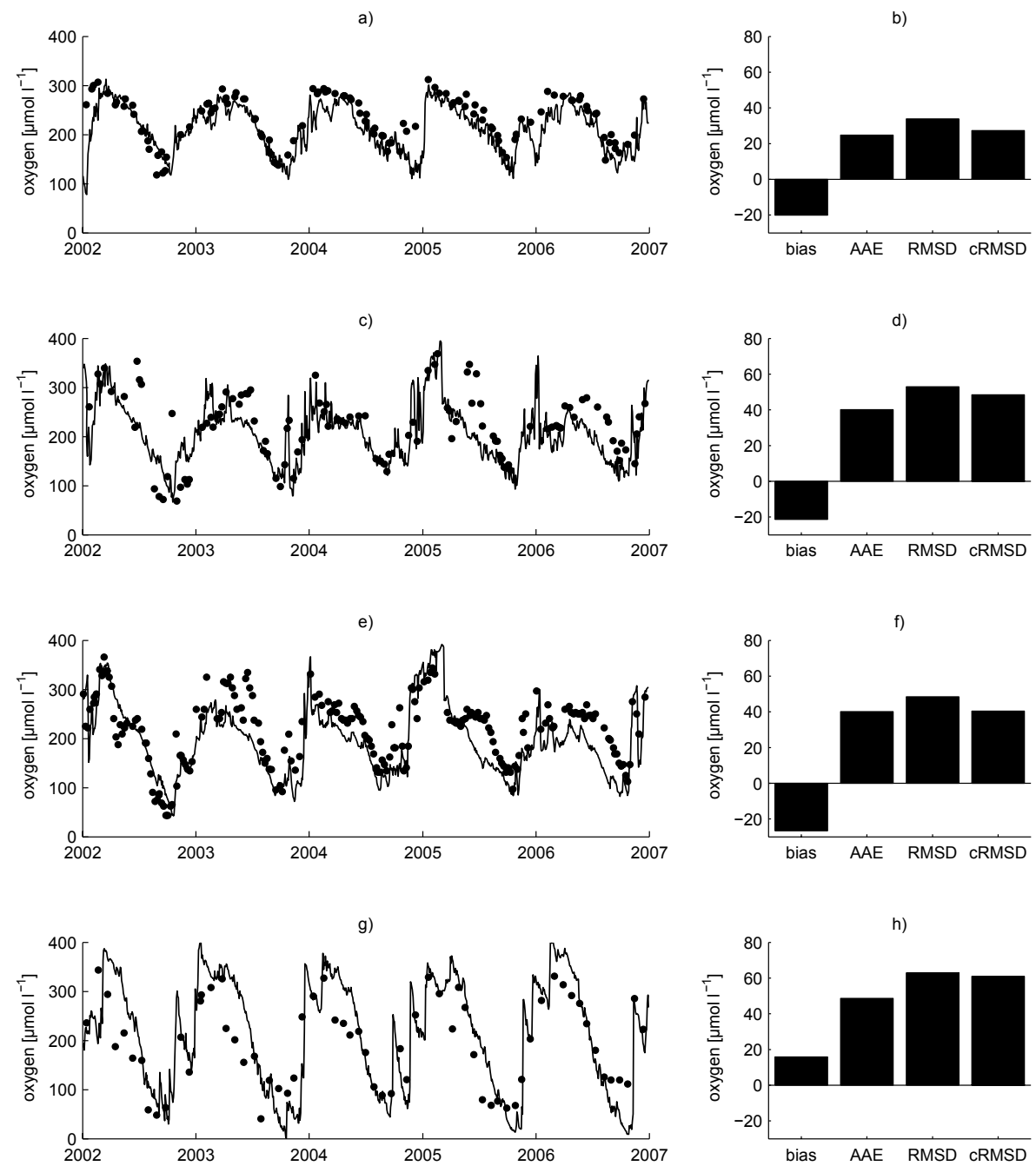

Fig. 4. Simulated (black line) and observed (black dots) DO concentrations together with statistical measures (right panels) for the bottom layer of the model at station (a, b) 413, (c, d) 925, (e, f) "gb" and (g, h) Arkona Basin.

a)

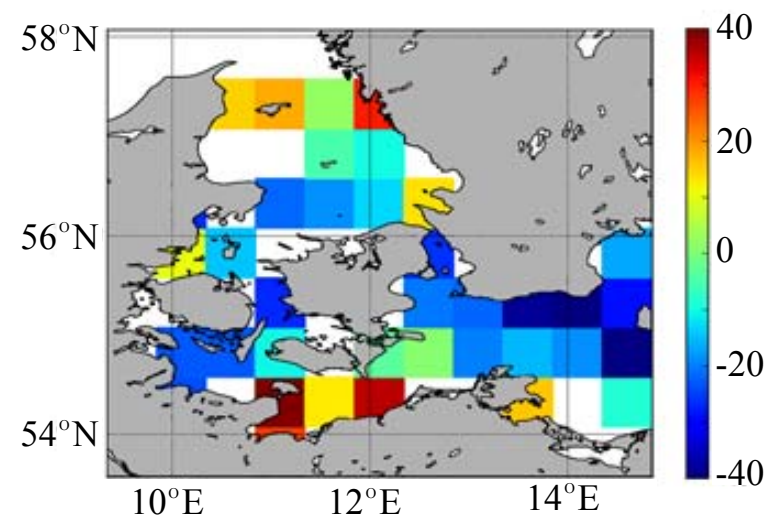

b)

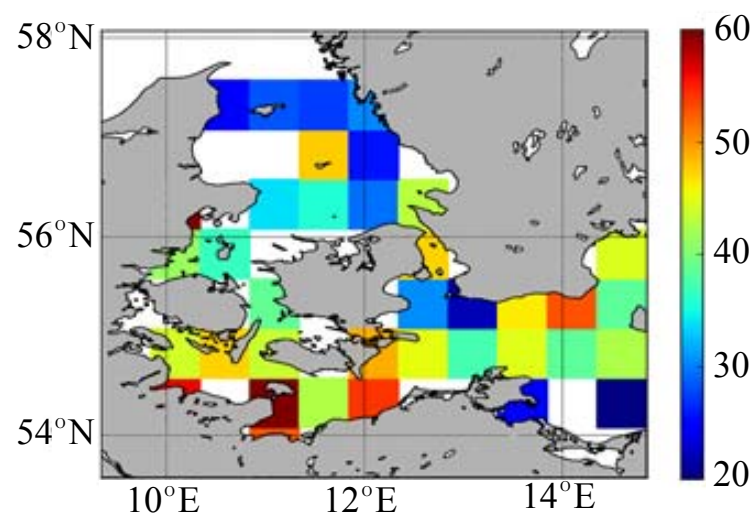

Fig. 5. Average spatial variation of the (a) oxygen bias and (b) average error during autumn for the years 2002-2006 (units in $\mu$ mol $1^{-1}$ ). 


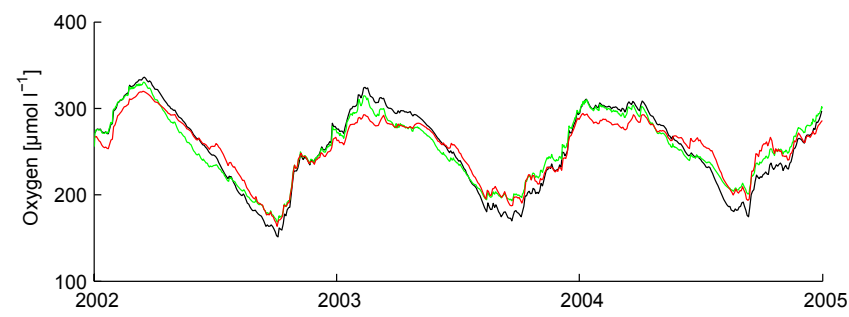

Fig. 6. Simulated mean oxygen concentration for the bottom water (below $15 \mathrm{~m}$ depth) in the oxygen model domain (Arkona basin excluded). The black line indicates the reference simulation, green line Simulation 1 with constant respiration rates and red line Simulation 2 with constant oxygen saturation at the surface.

during winter season. The accumulated transport below $15 \mathrm{~m}$ through the Northern Kattegat section (S1) and Great Belt section (S2) can be seen in Fig. 7b. Positive values indicate a transport from Skagerrak to Kattegat for S1 and from Kattegat through the Great Belt for S2. The inflow from Skagerrak to the bottom water of Kattegat varied seasonally with a stagnation period in summer. The flow rate though Great Belt was much more stable throughout the year. By comparing the accumulated transport through the two sections it is obvious that only a fraction of the volume passing S1 continues through Great Belt. During the three years, a volume of $2300 \mathrm{~km}^{3}$ was transported from Skagerrak to the bottom water of Kattegat but only $300 \mathrm{~km}^{3}$ continued through the Great Belt. This means that a major part of the inflowing Skagerrak water was entrained into the surface layer in Kattegat and moved northward in the anti-cyclonic circulation described by Nielsen (2005) before reaching the Great Belt.

The correlation between Skagerrak inflows and DO concentration at stations 413 appeared when the mean transport was subtracted from the accumulated transport at S1 (Fig. 8). The seasonal variations in bottom DO concentration were reflected in the variations in volumetric flow rate. The decreased DO concentration coincided with the stagnation period during spring and summer and larger inflows rapidly oxygenated the bottom water.

\subsection{Interannual variations}

The interannual variation of the hypoxic condition was clearly seen when comparing the monthly mean DO concentration in September 2002 and 2004. In 2002 large areas of hypoxic waters occupied Mecklenburg Bight and Little Belt, comprising an area of $3180 \mathrm{~km}^{2}$, and oxygen deficiency $\left(<126 \mu \mathrm{mol}^{-1}\right)$ covered large parts of western Kattegat and Great Belt (Fig. 9a). In 2004 only smaller patches of hypoxic water were visible $\left(706 \mathrm{~km}^{2}\right)$ and an even larger decrease was seen in the extent of oxygen deficiency (Fig. 9c). In the calculation of the mean hypoxic area Arkona Basin has been excluded for two reasons; (1) in order to ease the comparisons with other studies which usually do not include the basin,

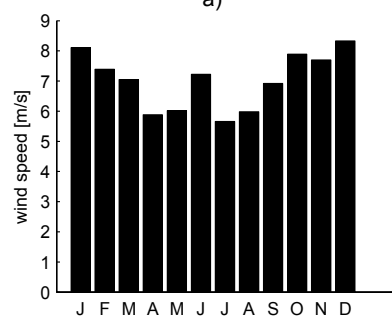

b)

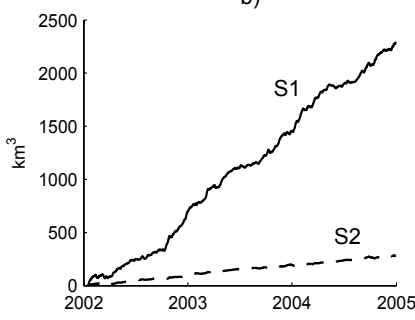

Fig. 7. (a) Monthly mean wind speed during the three years 2002 2004. (b) Integrated southward water transport below $15 \mathrm{~m}$ through the two sections $\mathrm{S} 1$ and $\mathrm{S} 2$.

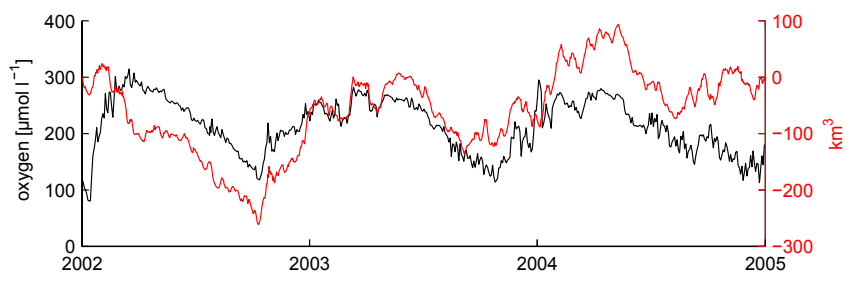

Fig. 8. Simulated DO concentration at station 413 (black line) and the deviations in the accumulated flow from the mean flow through S1 (red line). A negative (positive) gradient of the red line implies a lower (higher) volumetric flow rate then the mean.

e.g. HELCOM, (2003). (2) Arkona basin can be seen as a part of Baltic Sea and differs significantly from other parts of the region in for instance total depth, stratification strength, productivity and trophodynamics (Fennel, 1999).

The monthly mean wind speed in 2002 and 2004 was $5.9 \mathrm{~m} \mathrm{~s}^{-1}$ and $7.5 \mathrm{~m} \mathrm{~s}^{-1}$. In 2004, $11 \%$ of the recorded wind speeds were above $14 \mathrm{~m} \mathrm{~s}^{-1}$ with directions predominant from the west while in 2002 the maximum wind speed was $12.5 \mathrm{~m} \mathrm{~s}^{-1}$ with a more varying direction (Fig. 10). In both simulation 3 and simulation 4 the largest change in DO concentration was seen in shallow regions such as the southwest Kattegat and the southern Belt Seas (Fig. 9b and d). In 2002 the monthly mean hypoxia in September was decreased to $1900 \mathrm{~km}^{2}$ and in 2004 the area was increased to $1890 \mathrm{~km}^{2}$. It should be mentioned that in the end of August there was no significant difference in oxygen condition between the two years, actually, mid August in 2004 had a larger extent of hypoxia than in 2002. This shows the importance of wind induced mixing in regulating hypoxia but also that the wind speed itself could not account for the extreme event in 2002. In order to explain the remaining variations the accumulated transport through S1 were compared to the area of hypoxic water (Fig. 11).

The transport through the cross sections showed no significant modifications in the simulations with reduced or increased wind speed (Fig. 11b, d) and the development of hypoxia from July to the beginning of September were almost identical in 2002 and 2004. But in September the two years 

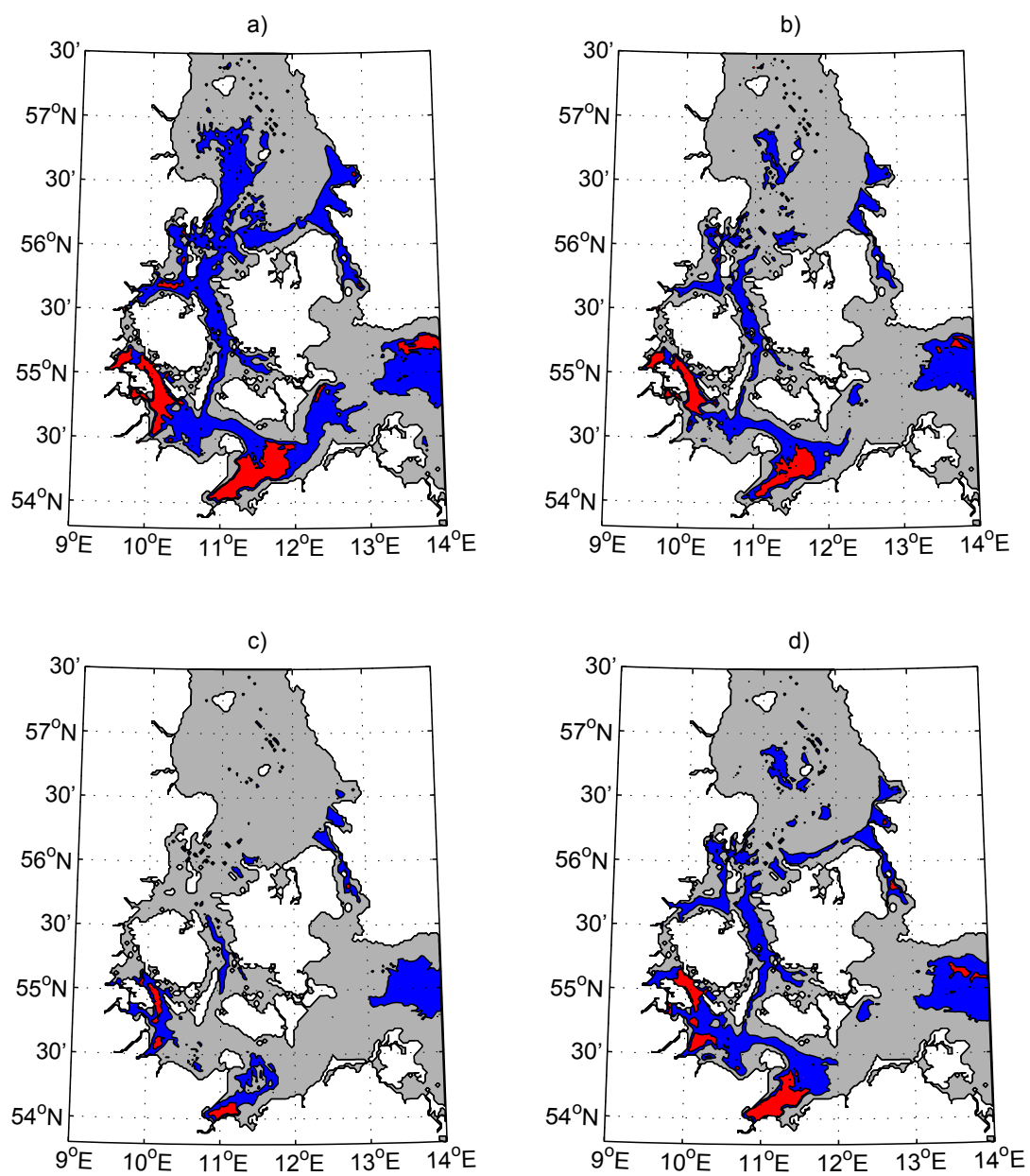

Fig. 9. Monthly averaged bottom DO concentration for (a) September 2002 and (b) September 2002 with increased wind and (c) September 2004 and (d) September 2004 with decreased wind. Red and blue patches indicate areas with hypoxia $\left(<63 \mu\right.$ mol $\left.1^{-1}\right)$ and oxygen deficiency $\left(<126 \mu \mathrm{mol}^{-1}\right)$ respectively.
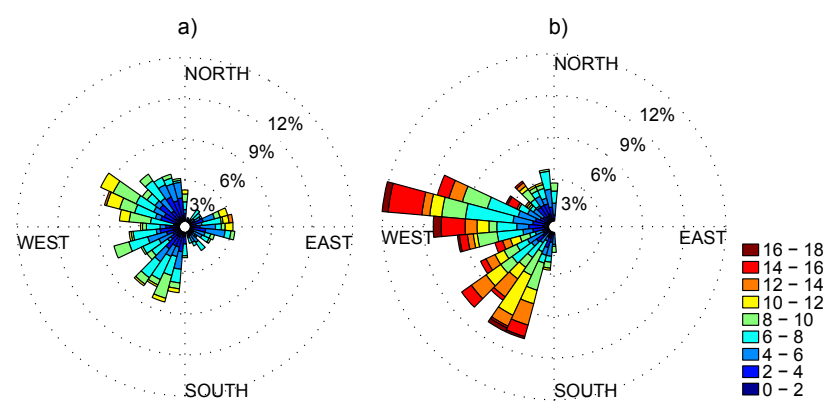

Fig. 10. Wind roses for (a) September 2002 and (b) September 2004. The length of each bar indicates the frequency of a particular wind direction and the colour of the bar indicates the wind speed.

differed significantly (Fig. 11a, c). In 2004 the bottom waters were ventilated concomitant with a larger inflow through S1 while in 2002 there was almost no transport through S1 and the hypoxia increased throughout September.

\section{Discussion}

\subsection{Seasonal variations in DO concentration}

The DO variation in the bottom water of the North SeaBaltic Sea transition zone follows an annual cycle with highest concentration in early spring and lowest in autumn. When the entire transition area is considered as a whole the annual variation is dominated by hydrodynamics, as the results showed that the seasonality of the respiration only accounted for $13 \%$ of the DO annual variation and the effect of the temperature and salinity dependent oxygen solubility contributed $24 \%$. Moreover, the effect of keeping the boundary condition constant was found to be negligible (not presented). This means that variations of local DO supply from the upper layer by mixing and horizontal advection must explain the major part of the bottom water variation. Local supply of DO to the bottom water is important in shallow regions where the halocline is easily weakened or collapsed 

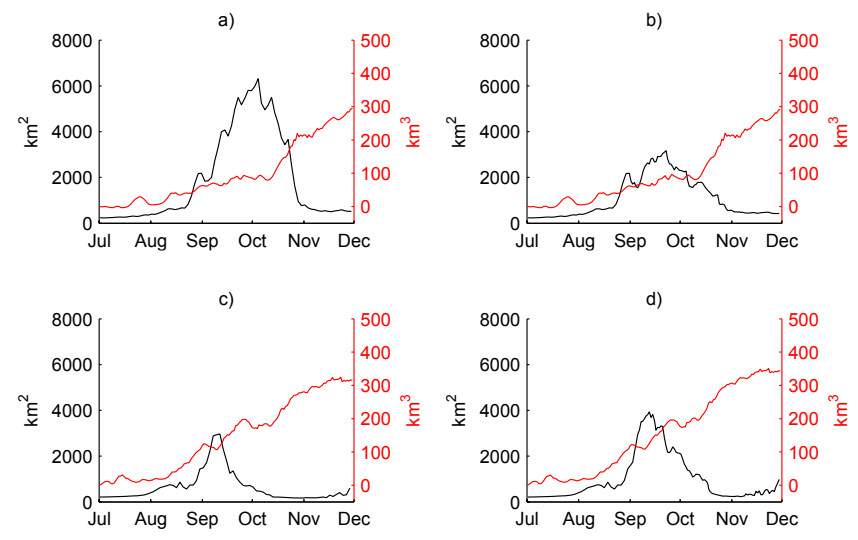

Fig. 11. The black line indicates time evaluation of hypoxic area in the domain (Arkona basin excluded) and the red line shows the integrated southward transport below $15 \mathrm{~m}$ across section $\mathrm{S} 1$ from 1 July to 30 November for (a) 2002, (b) 2002 with increased September wind, (c) 2004 and (d) 2004 with decreased September wind.

but in the relatively deep eastern Kattegat a persistent stratification prevents the ventilation and advective transport of DO plays the major role (Bendtsen et al., 2009).

In Fig. 12 the net DO transport across the two transects is compared against the respiratory sink. The advection at $\mathrm{S} 1$ is compared to the volume integrated respiration in the Kattegat bottom water east of the island Læsø. Since the transport through S1 almost exclusively occurs at the east side of Læs $\varnothing$ (Andersson and Rydberg, 1993) it was assumed that all water crossing S1 enters the volume. The net advection through S2 was compared to the respiration in a volume covering the bottom water from the entrance of Great Belt to Darss sill.

The results showed that the seasonal variation in the total respiratory oxygen consumption in the bottom water in the Kattegat, as parameterised in OXYCON, was much smaller than the seasonality in the amount of DO advected from Skagerrak (Fig. 12a). In winter the advective process was much larger than the respiration but because of a drastic decrease in the input of DO the two processes were more or less equal in summer. Approximately 250000 tons $\mathrm{O}_{2}$ month $^{-1}$ were advected to Kattegat in summer (June-August), 450000 tons $\mathrm{O}_{2}$ month $^{-1}$ in autumn (August-October) and 830000 tons $\mathrm{O}_{2}$ month $^{-1}$ in winter (November-February). These figures are in agreement with Andersson and Rydberg (1993), although they estimated a larger winter transport. As also assumed in OXY$\mathrm{CON}$, this documents that the variation of DO respiration is of minor importance to the seasonality of bottom DO in the Kattegat as a whole.

The water transport through the Great Belt (S2) was considerably smaller and at the same time the bottom water DO content has been reduced during the passage of the Kattegat, thereby amplifying the seasonal variation in the southward transport of DO. Here the variation in the DO transport was
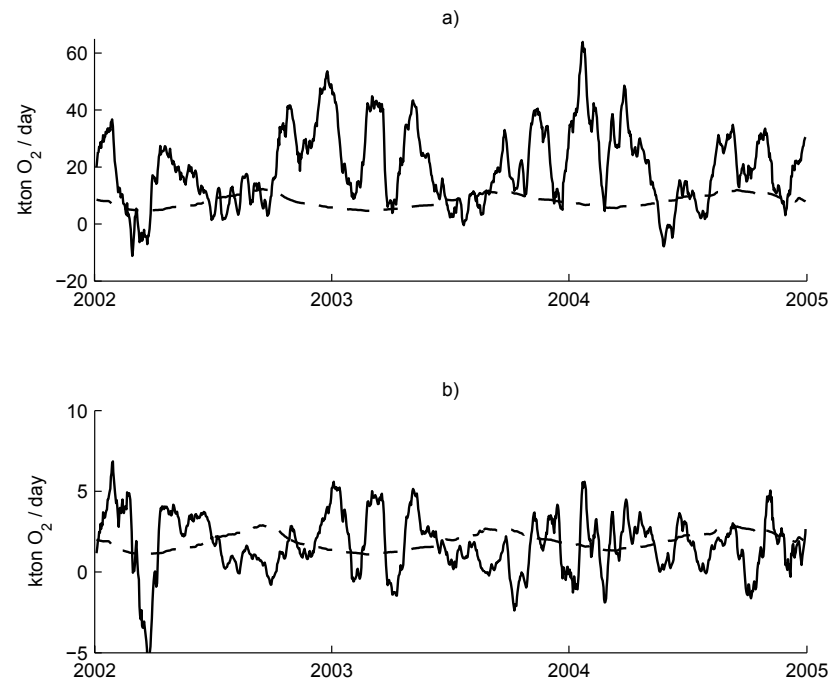

Fig. 12. Comparison between the advective DO input (solid line) and the respiratory sink (dotted line) for the bottom water of (a) Eastern Kattegat and (b) the Belt Seas. The DO flux is calculated by using the transport across S1 and S2 for Kattegat and Great Belt, respectively, and is smoothed with a one month running mean.

of the same magnitude as the variation in the respiration and the total advective DO supply was much less than the respiratory oxygen requirements in the areas south of the Great Belt. This is also the region where hypoxia is a reoccurring phenomenon during the late summer and autumn concomitant with the period where the respiratory oxygen demand consistently exceeds the DO transport through the Great Belt (e.g. Fig. 12b). Wind mixing plays a more prominent role in this area and, as shown in the simulation with increased wind, the deficit in advected DO can be compensated by increased wind mixing. Nevertheless, the DO transport across S2 is a very important factor in the regulation of DO in the Western Baltic Sea and better estimates of DO transport could potentially improve forecasts of hypoxia.

\subsection{Interannual variations of hypoxia}

The model nicely reproduced the interannual variation of hypoxia, especially the model predicted the extreme extent of hypoxia in 2002. Since the simulated respiration depends on temperature and was almost constant from year to year, the modelled interannual variation is mainly caused by the physical processes. The serious hypoxia in 2002 was likely caused by a combination of low vertical mixing and stagnant inflow from Skagerrak. The main difference in 2002 to other more normal years (referred to as 2004) was that the low wind speed did not ventilate the shallow areas in western Kattegat and southern Belt Seas. The fact that shallow areas are more affected by wind conditions is a consequence of three things: (1) the volume of the bottom water is less and gets easier ventilated by vertical mixing, (2) the salinity pool 
in the bottom water is less and the stratification is much easier broken down or weakened and (3) shallow areas develop hypoxia much faster than deeper areas because of the relatively larger contribution from benthic oxygen uptake from the shallower water column. However, the difference in wind speed did not completely explain the large differences between 2002 and 2004. In 2002 the stagnant bottom water prolonged the event and the deeper parts of Kattegat and Great Belt were not oxygenated until a larger inflow from Skagerrak occurred in the beginning of October. The inflowing Skagerrak water brings large amount of DO to the bottom water of Kattegat. Since bottom Kattegat water moves southward, mainly through the Great Belt, the inflow events will also affect the oxygen conditions further south. Another indirect effect of the inflowing water is that increased velocity shear may produce vertical turbulence and enhance the local supply of DO from the upper layer. This is specifically important in the narrow straits where the horizontal velocities can be rather large. Because of this mechanism Bendtsen et al. (2009) considered the Great Belt as a "breathing hole". The present study also emphasis the critical water flux through the bottom transect in the Great Belt for the ventilations of the Western Baltic Sea.

\section{Conclusions}

DO in the transition zone of the North Sea and Baltic Sea was simulated using a 3-D circulation model together with a simple parameterization of the respiratory sinks. The complex biogeochemical process controlling the oxygen consumption was simplified with a temperature dependent function for three processes: pelagic respiration, benthic respiration and diffusive sediment oxygen uptake. A quantitative assessment using more than 3000 observations showed that the model is able to simulate the DO in this region. The fact that this simplified treatment of the biogeochemical processes yielded such realistic results highlights the importance of physical processes in controlling the spatiotemporal variation of DO in open waters. There is a large difference in timescales between the physical and biogeochemical processes. A storm or an inflow event can supply large amount of DO to the bottom water within a couple of hours while the remineralisation of organic material continuously consumes oxygen during the summer, but at a much slower rate. A long term increase in export production because of e.g. eutrophication will lead to a larger consumption of oxygen and hypoxia may occur more frequent. In short term circulation and meteorological conditions are likely the dominating factors controlling DO and the extension of hypoxic areas. The general and long term oxygen conditions depend on the respiration rate and on the amount of oxygen imported to the transition zone across the northern border.
Table A1. Parameters.

\begin{tabular}{llr}
\hline Symbol & Meaning & Value \\
\hline$\beta$ & Oversaturation factor & 1.025 \\
$\alpha$ & Piston velocity & $5.2 \times 10^{-5} \mathrm{~m} \mathrm{~s}^{-1}$ \\
$\mu_{\mathrm{p}}$ & Pelagic respiration constant & $6.952 \times 10^{-6} \mu \mathrm{mol}$ \\
& & $\mathrm{O}_{2} 1^{-1} \mathrm{~s}^{-1}$ \\
$\mu_{\mathrm{b}}$ & Benthic respiration constant & $0.0464 \mu \mathrm{mol}$ \\
& $\mathrm{O}_{2} \mathrm{~m}^{-2} \mathrm{~s}^{-1}$ & $0.0338 \mu \mathrm{mol}$ \\
$\mu_{\mathrm{S}}$ & Constant for sediment uptake & $\mathrm{O}_{2} \mathrm{~m}^{-2} \mathrm{~s}^{-1}$ \\
& & $5.0 \mu \mathrm{mol}$ \\
$k_{\mathrm{p}}$ & Pelagic half-saturation constant & $\mathrm{O}_{2} 1^{-1}$ \\
$k_{\mathrm{b}}$ & Benthic half-saturation constant & $60.0 \mu \mathrm{mol}$ \\
$Q_{10}$ & Respiratory temperature effect & $\mathrm{O}_{2} 1^{-1}$ \\
$T_{\text {ref }}$ & Reference temperature & 3.0 \\
\hline
\end{tabular}

\section{Appendix A}

At each time step the coupled model solves the prognostic Eq. (A1)

$\frac{d \mathrm{O}_{2}}{d t}=\operatorname{adv}+\operatorname{diff}+\mathrm{O}_{2}^{\text {flux }}-R_{\mathrm{p}}-R_{\mathrm{b}}-R_{\mathrm{s}}$,

where "adv" and "diff" is advection and diffusion of DO and $\mathrm{O}_{2}^{\text {flux }}$ is oxygen flux through the sea surface. $R_{\mathrm{p}}, R_{\mathrm{b}}$ and $R_{\mathrm{s}}$ is the three different respiratory sinks described below. The oxygen flux through the sea surface is given in Eq. (A2) and applied at surface grid points. In line with Stigebrandt (1991) the surface water is assumed to be $2.5 \%$ over saturated because of the supply of oxygen from bubbles. Here, $\alpha$ is the piston velocity and $\beta$ is a scaling constant for the effects of bubbles and $\mathrm{O}_{2}^{\text {sat }}$ is the oxygen saturation concentration which is determined from salinity and temperature.

$\mathrm{O}_{2}{ }^{\text {flux }}=\alpha\left(\mathrm{O}_{2}^{\text {sat }} \cdot \beta-\mathrm{O}_{2}\right)$

The pelagic and benthic respiration is given by Eq. (A3). The pelagic respiration is applied at all water points while the benthic respiration is only applied at the bottom grid points.

$R_{i}=\mu_{i} Q_{10}^{\frac{T-T_{\mathrm{ref}}}{10}} \frac{\mathrm{O}_{2}}{\mathrm{O}_{2}+k_{i}}$,

the index $i$ should be interchange with benthic (b) and pelagic (p). $Q_{10}$ the exponential temperature dependence, $T$ and $T_{\text {ref }}$ the water temperature and the reference temperature and $k$ is the oxygen half saturation.

$R_{\mathrm{s}}=\mu_{\mathrm{s}} Q_{10}^{\frac{T-T_{\mathrm{ref}}}{10}} \frac{\mathrm{O}_{2}}{\mathrm{O}_{2}^{\mathrm{sat}}}$

The sediment oxygen uptake is given by a similar expression but is limited by the diffusive transport of oxygen into the 
sediment which is described by the saturation level. The formulation for this process is given in Eq. (A4) and it is applied at bottom grid points.

Parameter values can be found in Table A1.

Acknowledgements. This work was funded by the Danish Council for Strategic Research via ECODYN project. The authors would like to thank Jørgen Bendtsen who developed OXYCON together with Jørgen L. S. Hansen and kindly provided us with the oxygen consumption parameterization. Thanks are also due to Jesper Larsen for providing the validation software.

Edited by: E. Stanev

\section{References}

Andersson, L. and Rydberg, L.: Trends in nutrient and oxygen conditions within the Kattegat: Effects of local nutrient supply, Estuar. Coast. Shelf. S., 26, 559-579, 1988.

Andersson, L. and Rydberg, L.: Exchange of water and nutrients between the Skagerrak and the Kattegat, Estuar. Coast. Shelf. S., 36, 159-181, 1993.

Bendtsen, J., Gustavsson, K. E., Söderkvist, J., and Hansen, J. L. S.: Ventilation of bottom water in the North Sea-Baltic Sea transition zone, J. Marine Syst., 75, 138-146, 2009.

Carstensen, J., Conley, D. J., Andersen, J. H., and Ærtebjerg, G.: Coastal eutrophication and trend reversal: A Danish case study, Limnol. Oceanogr., 51, 398-408, 2006.

Conley, D. J., Carstensen, J., Ærtebjerg, G., Christensen, P. B., Dalsgaard, T., Hansen, J. L. S., and Josefson, A. B.: Long-term changes and impacts of hypoxia in Danish coastal waters, Ecol. Appl., 17, 165-184, 2007.

Diaz, R. J.: Overview of hypoxia around the world, J. Environ. Qual., 30, 275-281, 2001.

Fennel, K.: Convection and the Timing of Phytoplankton Spring Blooms in the Western Baltic Sea, Estuar. Coast. Shelf. S., 49, 113-128, 1999.

Gray, J. S., Wu, R. S., and Or, Y. Y.: Effects of hypoxia and organic enrichment on the coastal marine environment, Mar. Ecol.-Prog. Ser., 238, 249-279, 2002.

Hansen, J. L. S. and Bendtsen, J.: Effects of climate change on hypoxia in the North Sea - Baltic Sea transition zone, IOP. C. Ser. Earth Environ. Sci., 6, Copenhagen, Denmark, 10-12 March 2009, 302016, 2009.

Hansen, J. L. S. and Bendtsen, J.: A model of the oxygen dynamics in the North Sea - Baltic Sea transition zone with emphasis on the role of temperature, in preparation.

HELCOM: The 2002 oxygen depletion event in the Kattegat, Belt Sea and Western Baltic, Technical report, Baltic Sea Environment Proceedings No. 90, 2003.
Kiørboe, T., Lundsgaard, C., Olesen, M., and Hansen, J. L. S: Aggregation and sedimentation processes during a phytoplankton spring bloom: A field experiment to test coagulation theory, J. Mar. Res., 52, 297-323, 1994

Larsen, J., Høyer, J. L., and She, J.: Validation of a hybrid optimal interpolation and Kalman filter scheme for sea surface temperature assimilation, J. Marine Syst., 65, 122-133, 2007.

Lewis, K. and Allen, J. I.: Validation of a hydrodynamic-ecosystem model simulation with time-series data collected in the Western English Channel, J. Marine Syst., 65, 296-311, 2009.

Maar, M., Möller, F. E., Larsen, J., Madsen, S. K, Wan, Z., She, J., Jonasson, L., and Neumann, T.: Ecosystem modelling across a salinity gradient from the North Sea to the Baltic Sea, Ecol. Model., 222, 1696-1711, 2011.

Møhlenberg, F.: Effect of meteorology and nutrient load on oxygen depletion in a Danish micro-tidal estuary, Aquat. Ecol., 33, 5564, 1999.

Nash, J. E., and Sutcliffe, J. V.: River flow forecasting through conceptual models part 1-A discussion of principles, J. Hydrol., 10, 282-290, 1970.

Nielsen, H. M.: The baroclinic surface currents in the Kattegat, J. Marine Syst., 55, 97-121, 2005.

Oguz, T., Ducklow, H. W., and Malanotte-Rizzoli, P.: Modeling distinct vertical biogeochemical structure of the black sea: Dynamical coupling of the oxic, suboxic and anoxic layers, Global Biogeochem. Cy., 14, 1331-1352, 2000.

Olesen, M. and Lundsgaard, C.: Seasonal sedimentation of autochthonous material from the euphotic zone of a coastal system, Estuar. Coast. Shelf S., 41, 475-490, 1995.

Rykiel, Jr., E. J.: Testing ecological models: the meaning of validation, Ecol. Model., 90, 229-244, 1996.

She, J., Berg, P., and Berg, J.: Bathymetry impacts on water exchange modelling through the Danish Straits, J. Marine Syst., 65, 450-459, 2007.

Skyum, P., Christiansen, C., Lund-Hansen, L. C., and Nielsen, J.: Advection-induced oxygen variability in the North Sea-Baltic Sea transition, Hydrobiologia, 281, 65-77, 1994.

Stigebrandt, A.: Computations of oxygen fluxes through the sea surface and the net production of organic matter with application of the Baltic and adjacent seas, Limnol. Oceanogr., 36, 444-454, 1991.

Vichi, M. and Masina, S.: Skill assessment of the PELAGOS global ocean biogeochemistry model over the period 1980-2000, Biogeosciences, 6, 2333-2353, doi:10.5194/bg-6-2333-2009, 2009.

$\mathrm{Xu}, \mathrm{J}$. and Hood, R. R.: Modeling biogeochemical cycles in Chesapeake Bay with a coupled physical-biological model, Estuar. Coast. Shelf, S., 69, 19-46, 2006.

Wan, Z., Jonasson, L., and Bi, H.: N/P ratio of nutrient uptake in the Baltic Sea, Ocean Sci., 7, 693-704, doi:10.5194/os-7-693-2011, 2011. 